\title{
Airborne Microplastics from Waste as a Transmission Vector for COVID-19
}

\section{Aerosol and Air Quality Research}

Special Issue:

Special Issue on COVID-19 Aerosol Drivers, Impacts and Mitigation (IX)

\section{Qingyang Liu ${ }^{1 *}$, James Schauer ${ }^{2,3}$}

${ }^{1}$ Co-Innovation Center for the Sustainable Forestry in Southern China, College of Biology and the Environment, Nanjing Forestry University, Nanjing 210037, China

${ }^{2}$ Environmental Chemistry and Technology Program, University of Wisconsin-Madison, Madison, Wisconsin 53706, USA

${ }^{3}$ Wisconsin State Laboratory of Hygiene, University of Wisconsin-Madison, Madison, Wisconsin 53718, USA

\section{ABSTRACT}

Occurrences of microplastics (plastic particle $<5 \mathrm{~mm}$ ) have been observed in various environmental media (e.g., soil, water and air) worldwide, posing a threat to ecological, human, and animal health. Microplastics could also serve as vectors which transport toxic hydrophobic organic compounds around the globe and negatively affect the environmental quality. This paper analyzes the possible link between airborne microplastics from waste that are contaminated with SARS-CoV-2, and the transmission of SARS-CoV-2. In addition, measures for controlling the transmission of SARS-CoV-2 in airborne microplastics were discussed. Our study indicates that precautionary action regarding the management of contaminated plastic waste should be considered in order to combat the spread of SARS-CoV-2 through airborne microplastic.

Keywords: COVID-19, Airborne microplastics, Vector, Transmission

Coronavirus disease 2019 (COVID-19), which is caused by a novel coronavirus, SARS-CoV-2, has spread to more than 200 nations worldwide since the infection was first discovered in Wuhan, China, in late December 2019 (WHO, 2020). The global spread of the new coronavirus has led to the infection of more than 35 million people and to the death of 1,100,000, as of October 16 , 2020 (https://www.worldometers.info/coronavirus/). The global impact continues to increase. On March 11, 2020, the WHO declared COVID-19 a pandemic because of its threat to global public health. The transmission efficiency of SARS-CoV-2 has been found to be higher than that of other infectious coronaviruses, including those causing severe acute respiratory syndrome (SARS-CoV) and Middle East respiratory syndrome (MERS-CoV) (Kraemer et al., 2020). The Human Development Index (HDI), as defined by The United Nations Development Program (UNDP), is a measure to describe the level of human development across different countries. It combines the gross national income index, an education index, and a life expectancy index (Liu et al., 2019). Chennakesavulu et al. (2020) found that countries with high HDI values, in the range of 0.700-0.935, reported more than $80 \%$ of the coronavirus cases collected from December 31, 2019 to April 25, 2020. Nevertheless, the level of HDI did not appear to be a factor in controlling the transmission efficiency of SARS-CoV around the world. Rather, at below $20^{\circ} \mathrm{C}$, ambient temperature was the dominant factor in the spreading of coronavirus (Chennakesavulu et al., 2020). The spread of SARS-CoV increased with decreasing temperature at below $20^{\circ} \mathrm{C}$ (Chennakesavulu et al., 2020). Still the transmission pathways for this coronavirus in environmental media have not fully illustrated.

At the beginning of the COVID-19 outbreak in late December 2019, it was found that SARSCoV-2 originated from animals, and was then transmitted to humans at a wet market in Wuhan, China. Subsequent research has shown that the COVID-19 infection is spread in the community via respiratory transmission, as well as touching surfaces contaminated with SARS-CoV-2 and 
then transferring the virus to the mouth, nose, and eyes (Kraemer et al., 2020). The coronavirus present on human skin and environmental surfaces can be eliminated with the use of disinfectants (Kraemer et al., 2020). Inhalation of aerosol droplets containing SARS-CoV-2 is thought to be an important pathway for the spread of COVID-19, and has been a key research topic (Hsiao et al., 2020; Liu et al., 2020; Morawska and Cao, 2020; Prather et al., 2020; Zhang et al., 2020c). For example, Zhang et al. (2020c), after analyzing the data collected from Wuhan, China, Italy, and New York City, deduced that airborne transmission was the dominant route for the spread of COVID-19. Likewise, social distancing and the use of personal protective equipment (PPE), including face masks and gloves, are the effective strategies to prevent contact with coronavirus (Hale and Song, 2020; Kraemer et al., 2020). These measures have been demonstrated as effective for reducing the transmission, as well as the economic and health impacts, of COVID-19 on a global scale (Morawska and Cao, 2020; Prather et al., 2020).

Since plastics (e.g., polypropylene, polyurethane) are an integral part of face masks and gloves, and their waste is a known source of environmental pollution (Akdogan and Guven, 2019; Caruso, 2019), the waste management of personal protective equipment contaminated with SARS-CoV-2 has received wide concern globally (Hale and Song, 2020). Mismanagement of plastic waste containing SARS-CoV-2 could lead to the contamination of waters (Wang et al., 2020), thus highlighting the importance of managing wastewater systems efficiently in order to combat the spread of SARS-CoV-2 at a local and regional scale (Wang et al., 2020). On the basis of direct evidence for the role of environmental factors in the spreading of COVID-19, this study aims to discuss the possibility of SARS-CoV-2 transmission through airborne microplastics, and the associated mitigation measures.

Though most plastic waste is unable to decompose in a short period, fragments of medical waste plastics (i.e., microplastics) and larger medical plastic debris is produced due to weathering and degradation (e.g., aging and abrasion) (Zhang et al., 2020a) and even general use (Sobhani et al., 2020). Sobhani et al. (2020) found that microplastics smaller than 10 microns are generated by opening and manipulating plastics (e.g., containers, bags, tapes) with the use of scissors, hands, or knives, even the handling of garments made of plastic material (e.g., polyester). These processes were estimated to emit hundreds to tens of thousands of microplastics (Sobhani et al., 2020). The amounts of generated microplastics are dependent on the physical conditions of the plastic materials, including stiffness, thickness, anisotropy, and density. Nevertheless, microplastics smaller than 10 microns are easily suspended in the air and transported through air movements (Zhang et al., 2020a). Field experiments across numerous countries have documented that microplastics have been found in indoor dust (Zhang et al., 2020b). Microplastics suspended in the air have also been observed in outdoor environments in different regions, including East Asia, West Europe, West Pacific Ocean, South Asia, and Middle East (Prata, 2018; Zhang et al., 2020a).

A recent study has shown that SARS-CoV-2 is capable of surviving in aerosol droplets for $\sim 3$ hours and on plastic surfaces for 72 hours at room temperature $\left(20^{\circ} \mathrm{C}\right)$ and a relative humidity of $40 \%$. However, the amounts of the virus in the environmental matrices were significantly reduced during the study period (van Doremalen et al., 2020). Under environmental circumstances, SARS-CoV-2 on the surface of used gloves and face masks could still pose a threat to public health if the waste plastics are not properly collected and disposed of (Fig. 1) (Wang et al., 2020).

As plastic materials have been shown to emit even hundreds of microplastics with regular usage (Sobhani et al., 2020), PPE waste contaminated with SARS-CoV-2 could be a troublesome emission source if not managed properly. SARS-CoV-2 on smaller pieces of microplastics $(<10$ microns) emitted from the PPE waste could then become airborne and transported downwind or through ventilation systems, from indoor to outdoor environments, as well as from urban to remote areas. A recent field study has shown that, in France, airborne microplastics could be transported to remote sites, which were as far away as $95 \mathrm{~km}$ from the source, with the aid of strong airflow (Allen et al., 2019). Because SARS-CoV-2 is able to survive longer on the surface of plastic $(\sim 72 \mathrm{~h}$ ) than in aerosol droplets ( $\sim 3 \mathrm{~h})$, airborne microplastics, of waste plastics containing SARS-CoV-2, would extend the transmission of viable SARS-CoV-2 in the atmosphere for much longer times and distances. Since SARS-CoV- 2 remains viable on plastics for $\sim 72$ hours, the transmission route through airborne microplastics is expected to influence, not only individual countries, but also larger regions and the whole world. 


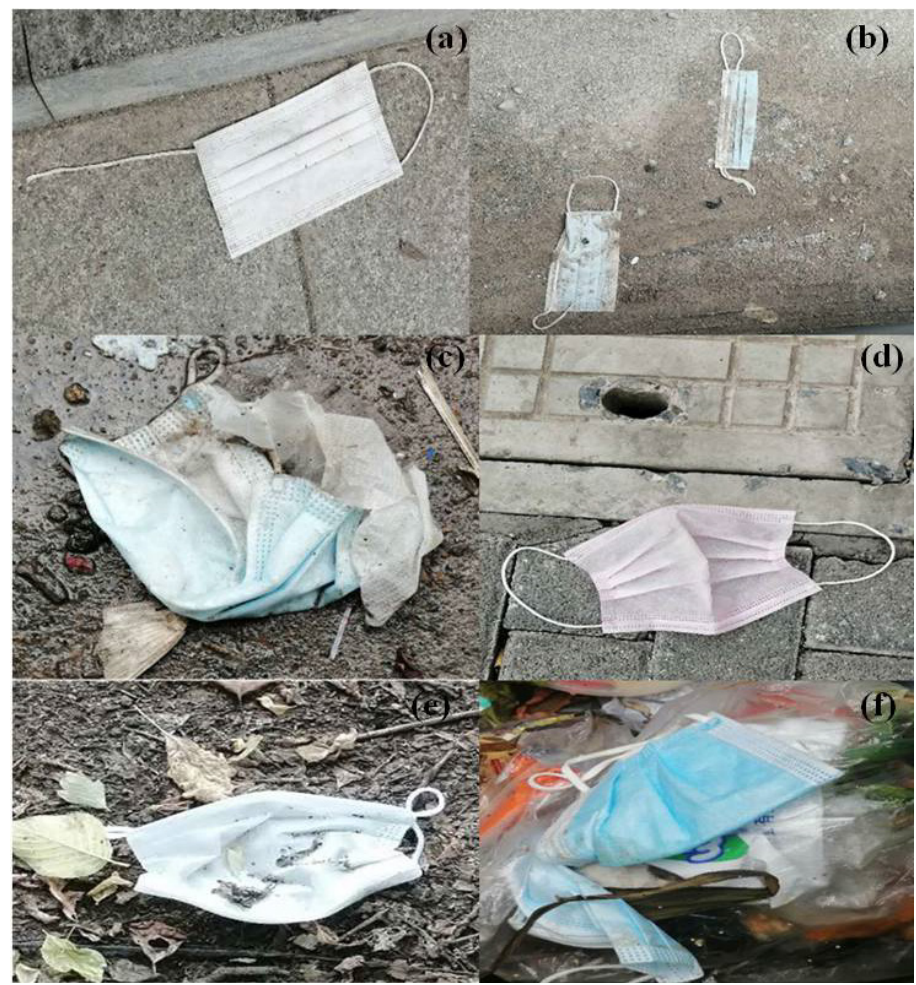

Fig. 1. The improper disposal cases of personal protection equipment during COVID-19 pandemic in China. Photo credits: the authors.

As discussed above, the existing findings on the survival lifetime of coronavirus on plastics emphasizes the need to heed caution globally against the airborne transmission of SARS-CoV-2 on microplastics. Since microplastic emission cannot be entirely avoided during the waste management process, effective sanitization procedures should be taken during the collection process of used plastics waste (Wang et al., 2020). The collections of plastic waste, including used face masks and gloves, should be separated from urban waste before disposal. For those areas (e.g., suburban and rural areas) where waste management, such as sophisticated waste segregation and other treatment methods, is not effectively available, incineration is an ideal method for preferential treatment of plastic waste contaminated by the virus because the virus is unable to survive at high temperatures.

\section{CONCLUSION}

International collaborations on the prevention and the control of SARS-CoV-2 transmission routes are necessary to build resilience for combating the spread of the COVID-19 pandemic on a local, regional, and global scale. Research and data sharing on the transmission routes of SARSCoV-2 through aerosols and airborne microplastics could help advance the international collaborations in combating the global threats associated with COVID-19. Improper disposal of PPE allows for continued microplastic emission to the air, and if contaminated with SARS-CoV-2 provides an additional transmission vector for the coronavirus. Future actions should focus on the proper management of plastic waste contaminated with SARS-CoV-2, including used medical face masks and gloves, in order to combat the spread of novel coronavirus through microplastics. The incentives for technological development in the management of plastic waste could reduce the environmental pollution associated with treatment methods for plastic waste.

\section{COMPETING FINACIAL INTEREST}

The authors declare no competing financial interest. 


\section{ACKNOWLEDGEMENT}

This research did not receive any specific grant from funding agencies in the public, commercial, or not-for-profit sectors.

\section{REFERENCES}

Akdogan, Z., Guven, B. (2019). Microplastics in the environment: A critical review of current understanding and identification of future research needs. Environ. Pollut. 254, 113011. https://doi.org/10.1016/j.envpol.2019.113011

Allen, S., Allen, D., Phoenix, V.R., Le Roux, G., Durántez Jiménez, P., Simonneau, A., Binet, S. Galop, D. (2019). Atmospheric transport and deposition of microplastics in a remote mountain catchment. Nat. Geosci. 12, 339-344. https://doi.org/10.1038/s41561-019-0335-5

Caruso, G. (2019). Microplastics as vectors of contaminants. Mar. Pollut. Bull. 146, 921-924. https://doi.org/10.1016/j.marpolbul.2019.07.052

Chennakesavulu, K., Reddy, G.R. (2020). The effect of latitude and PM 2.5 on spreading of SARSCoV-2 in tropical and termperate zone countries. Environ. Pollut. 266, 115176. https://doi.org/ 10.1016/j.envpol.2020.115176

Hale, R.C., Song, B. (2020). Single-use plastics and COVID-19: Scientific evidence and environmental regulations. Environ. Sci. Technol. 54, 7034-7036. https://doi.org/10.1021/ac s.est.0c02269

Hsiao, T.C., Chuang, H.C., Griffith S.M., Chen, S.J., Young, L.H. (2020). COVID-19: An aerosol's point of view from expiration to transmission to viral-mechanism. Aerosol Air Qual. Res. 20, 905-910. https://doi.org/10.4209/aaqr.2020.04.0154

Kraemer, M.U.G., Yang, C.H., Gutierrez, B., Wu, C.H., Klein, B., Pigott, D.M., du Plessis, L., Faria, N.R., Li, R., Hanage, W.P., Brownstein, J.S., Layan, M., Vespignani, A., Tian, H., Dye, C., Pybus, O.G., Scarpino, S.V. (2020). The effect of human mobility and control measures on the COVID-19 epidemic in China. Science 368, 493-497. https://doi.org/10.1126/science.abb4218

Liu, Q., Baumgartner, J., de Foym B., Schauer, J.J. (2019). A global perspective on national climate mitigation priorities in the context of air pollution and sustainable development. City Environ. Interact. 1, 100003. https://doi.org/10.1016/j.cacint.2019.100003

Liu, Y., Ning, Z., Chen, Y., Guo, M., Liu, Y., Gali, N.K., Sun, L., Duan, Y., Cai, J., Westerdahl, D., Liu, X., Xu, K., Ho, K., Kan, H., Fu, Q., Lan, K. (2020). Aerodynamic analysis of SARS-CoV-2 in two Wuhan hospitals. Nature 582, 557-560. https://doi.org/10.1038/s41586-020-2271-3

Morawska, L., Cao, J. (2020). Airborne transmission of SARS-CoV-2: The world should face the reality. Environ. Int. 139, 105730. https://doi.org/10.1016/j.envint.2020.105730

Prata, J.C. (2017). Airborne microplastics: Consequences to human health? Environ. Pollut. 234, 115-126. https://doi.org/10.1016/j.envpol.2017.11.043

Prather, K.A., Wang, C.C., Schooley, R.T. (2020). Reducing transmission of SARS-CoV-2. Science 368, 1422-1424. https://doi.org/10.1126/science.abc6197

Sobhani, Z., Lei, Y., Tang, Y., Wu, J., Zhang, X., Naidu, R., Megharaj, M., Fang, C. (2020). Microplastics generated when opening plastic packaging. Sci. Rep. 10, 4841. https://doi.org/ 10.1038/s41598-020-61146-4

van Doremalen, N., Bushmaker, T., Morris, D.H., Holbrook, M.G., Gamble, A., Williamson, B.N., Tamin, A., Harcourt, J.L., Thornburg, N.J., Gerber, S.I., Lloyd-Smith, J.O., de Wit, E., Munster, V.J. (2020). Aerosol and surface stability of SARS-CoV-2 as compared with SARS-CoV-1. N. Engl. J. Med. 382, 1564-1567. https://doi.org/10.1056/NEJMc2004973

Wang, J., Shen, J., Ye, D., Yan, X., Zhang, Y., Yang, W., Li, X., Wang, J., Zhang, L., Pan, L. (2020). Disinfection technology of hospital wasters and wastewater: Suggestions for disinfection strategy during coronavirus disease 2019 (COVID-2019) pandemic in China. Environ. Pollut. 262, 114665. https://doi.org/10.1016/j.envpol.2020.114665

World Health Organization (WHO) (2020). Laboratory testing of 2019 novel coronavirus (2019$\mathrm{nCoV}$ ) in suspected human cases: Interim guidance, 17 January 2020. World Health Organization. https://apps.who.int/iris/handle/10665/330676 
Zhang, J., Wang, L., Kannan, K. (2020b). Microplastics in house dust from 12 countries and associated human exposure. Environ. Int. 134, 113011. https://doi.org/10.1016/j.envint.2019. 105314

Zhang, Q., Xu, E.G., Li, J., Chen, Q., Ma, L., Zeng, E.Y., Shi, H. (2020a). A review of microplastics in table salt, drinking water, and air: Direct human exposure. Environ. Sci. Technol. 54, 37403751. https://doi.org/10.1021/acs.est.9b04535

Zhang, R., Li, Y.X., Zhang, A.L., Wang, Y., Molina, M.J. (2020c). Identifying airborne transmission as the dominant route for the spread of COVID-19. Proc. Natl. Acad. Sci. U.S.A. 117, 1485714863. https://doi.org/10.1073/pnas.2009637117 